\title{
The Influence of Guests' Social Interaction on the Hostel Experience: A Conceptual Framework
}

\author{
Jasmine Zea Raziah Radha Rashid-Radha ${ }^{a^{*}}$, Andrew Lockwood ${ }^{\mathrm{b}}$, Eimear-Marie Nolan-Davisc \\ ${ }^{a}$ School of Tourism, Hospitality and Environmental Management, Universiti Utara Malaysia, Kedah, Malaysia \\ ${ }^{b}$ School of Hospitality and Tourism Management, University of Surrey, United Kingdom \\ 'School of Busniess, Monmouth University, Unites States \\ *Corresponding author: jasmine@uum.edu.my
}

\begin{abstract}
Social interaction among fellow travellers forms a significant component of the authentic backpacking experience. Hostel accommodation have been purposely designed to provide the kind of environment that fosters communication and interaction between backpackers. Hostel guests have typically been provided with dormitory-type rooms, shared washrooms, kitchen and living areas, thus offering less privacy but more opportunity for social interaction. Few studies to date have fully investigated how social interaction among customers actually enhance or damage the service experience. Therefore, building on previous studies on servicescapes, co-creation and backpacker tourism, a conceptual framework is developed to examine how the hostel environment could be manipulated to influence guests' social interaction, and consequently their evaluation of the hostel service experience.
\end{abstract}

Keywords: Service experience, servicescapes, cross-cultural interaction, backpackers, hostelling

(C) 2016 Penerbit UTM Press. All rights reserved

\subsection{INTRODUCTION}

Past studies have revealed a major change in backpacking trends, which has led to a change in demand for certain hostel facilities and services (Cohen, 2003; Richards \& Wilson, 2004; O’Reilly, 2006; Markward, 2008; Cave, Thyne \& Ryan, 2008; Butler, 2010). Instead of enjoying the shared communal spaces offered by hostels, there is an increasing demand among guests for hostels to provide facilities and services that offer more privacy, security and personal space (Cave et al., 2008). For instance, older backpackers, particularly those on a career break and those who have greater disposable incomes, generally would rather spend more money on accommodation as they prefer to travel in comfort (Hannam \& Diekman, 2010; Jarvis \& Peel, 2010; Paris, 2012). Consequently, hostels need to ascertain if they are providing the right services and facilities that meet the changing requirements of their target market. This is especially important if a hostel is to attract the right market segment and remain competitive in the backpacking industry.

This research suggests that the hostel service environment has the potential to enhance social interaction among guests, thereby providing them with a favourable hostelling experience. The term 'servicescape' was introduced by Bitner (1992) to describe the physical environment of a service setting. Previous studies examining how servicescapes affect consumer behaviour indicate that in theory, the deliberate positioning and design of space, equipment, furniture and fixtures can influence the behaviour and interaction of consumers (Mehrabian \& Russell, 1974; Donovan \& Rossiter, 1982; Murphy, 2001; Kwortnik, 2008; Harris \& Ezeh, 2008). In addition, servicescapes may also play a part in consumers' evaluation of the service experience. For instance, a hostel dormitory room that appears old and neglected, or a communal dining area that is dirty and disorderly, may well contribute towards a very unpleasant service experience.

While a great deal of research has examined different elements of the servicescape that influence service experience (Kotler, 1973; Bitner, 1992; Hoffman \& Turley, 2002; Ezeh \& Harris, 2007), few studies to date have investigated how social interaction among customers can enhance or damage the service experience. To date, several studies focusing on cruise tourism have shown that social interaction among passengers significantly influences their overall vacation experience (Kwortnik, 2008; Huang \& Hsu, 2009a; Papathanassis, 2012). This research therefore intends to contribute to the further expansion of knowledge in the area of servicescapes by investigating the relationship between servicescape design, social interaction and service experience.

\subsection{LITERATURE REVIEW}

\section{Physical and Social Dimensions of the Servicescape}

The term 'servicescape' was originally introduced by Bitner (1992) to describe the physical environment of an organisation encompassing several different elements such as overall layout, design and décor. In the context of retail settings for instance, servicescapes are designed to influence consumer response behaviours such as stay/leave or browse/purchase, as well as social interaction (Donovan \& Rossiter, 1982). 
However, several researchers have demonstrated that the servicescape elements should not be limited to just the physical environment of the service setting (Martin, 1995; Tombs \& McColl-Kennedy, 2003; Harris \& Ezeh, 2008; Hall, 2009; Nicholls, 2010; Huang \& Hsu, 2010). Harris and Ezeh (2008) argue that the servicescape aspect should also include the behaviour and image portrayed by employees, as these factors also affect the customer's service experience. Furthermore, empirical studies carried out by Tombs and McColl-Kennedy (2003) have demonstrated that other customers present within the service setting have an important role in either enhancing or damaging the service experience. Their study highlighted that for a large birthday party at a buffet-style restaurant, for instance, the ambience may be enhanced by lively, friendly banter between customers. In contrast, a couple anticipating a romantic dinner for two would perhaps consider such behaviour inappropriate as they may wish for more privacy. Martin (1995), Hall (2009), Huang and Hsu (2009a), Nicholls (2010) and Nilsson and Ballantyne (2014), also acknowledge that customers' interaction with other customers create part of the servicescape atmosphere.

Despite the importance of servicescapes in facilitating social interaction, little attention has been paid to how the different elements of servicescape influence social interaction. Although several researchers (Mehrabian \& Russell, 1974; Argyle, Furnham \& Graham, 1981; Holahan, 1982; Levy, Getz \& Hudson, 2011; Bowie \& Buttle, 2011) have suggested that the physical environment may influence consumer behaviour in terms of social interaction, there have been very little empirical findings that support this notion. This implies that one can use the physical environment to influence customer interactions. In other words, tangible aspects of the service setting such as furniture, interior decor and space layout may be purposely designed to create the right ambiance that will encourage individuals to socialise with one another.

Referring specifically to backpackers' preferences in accommodation, several studies have drawn attention to the different aspects of hostel servicescapes that influence backpackers' evaluation of the service experience. According to Hecht and Martin (2006), the top five preferences are cleanliness, location, personal service, security, and hostel services such as Internet and laundry facilities. Additionally, Musa and Thirumoorthi (2011) highlighted that besides the tangible aspects of hostel operations such as equipment, facilities and cleanliness, the hostel's social ambience also contribute towards a positive service experience. Their studies indicate that the social ambience is created not only by the physical aspect of the hostel, but also by the way staff and guests interact with each other. The presence and behaviour of staff and guests create a special atmosphere which is described as cosy, friendly and home-like.

\section{Service Experience in Backpacker Hostels}

The existence of a relaxed, tolerant and socially permissive atmosphere is very much what attracts backpackers from all over the world to a particular destination (Westerhausen \& MacBeth, 2003). Richards and Wilson (2004) claim that this is arguably one of the major reasons for the development of backpacker enclaves in different parts of the world. These enclaves, sometimes called 'traveller centres', 'backpacker meccas' or 'backpacker ghettoes' (Teo \& Leong, 2006), are usually the most common meeting place for fellow travellers. According to Wilson and Richards (2008), enclaves can be found in chaotic commercial districts as well as rural areas with low accessibility. These enclaves provide a 'safe haven' when the pressure of the host culture forces backpackers to congregate in places that provide the company, support and information from fellow travellers (Hottola, 2005). The enclave is established as a place where other backpackers offer a surrogate cultural experience that is more akin to the home culture of the traveller (Wilson \& Richards, 2008). Drawing from this, the present research suggests that the presence of an environment that provides for the social needs of the backpackers is very important in attracting this market segment. There is therefore a need to understand exactly how these needs can be met, especially in terms of the provision of services and facilities.

The development of hostels and other inexpensive accommodation is one of the most important components of an enclave (Howard, 2007). The infrastructure that is created in the backpacker enclaves often differ from one place to another depending on the size, centrality of location in a city, number of nearby tourist attractions, host nation's culture, wealth and visa policies (Howard, 2007). Most enclaves provide essential tourist services such as accommodation, travel agencies, bars, Internet access and laundry facilities and are used by backpackers for various purposes. Besides 'getting away' from the locals and socialising with fellow travellers, Howard's (2007) survey showed that backpackers have used enclaves in several different ways. Some seek out enclaves purely for convenience, to arrange onward travel, for inexpensive accommodation and for some backpackers, as a party destination in itself. For backpackers who want to be surrounded by comforts from home, the enclave provides a safe bubble from which the backpackers can gaze out at the unfamiliar (Lloyd, 2003). The privacy of hostel rooms provides backpackers with the opportunity to retreat, be alone and experience 'suspension' from foreign travel. The present research therefore proposes that there is a need to understand how backpackers make use of the facilities and services being offered to meet their varying needs for both privacy and social interaction. This is because although backpackers enjoy the social experience of meeting other travellers within the enclaves, there are times that having some time alone in a private place is much welcomed.

Due to global demand, coupled with the current financial crisis, the hostel sector is also attracting families and businesses travellers who are travelling on a budget (Cave, Thyne \& Ryan, 2008; Mintel, 2009). Besides the low costs compared to hotel accommodation, hostel guests also have the opportunity to meet other like-minded travellers. Previous studies on the historical development of hostels have established that originally, hostels were purposely built to foster communication and interaction between hostellers (Biesanz, 1941; McCulloch, 1992; Dubin, 2003; Bowen \& Daniels, 2006). Getting to know fellow travellers is considered part of the product and experience of hostelling thus, the communal nature of hostel design helps facilitate this social interaction. Facilities such as bars, reading rooms, TV rooms and a common kitchen are important venues in the sociability of the hostel establishment as these areas provide opportunities for hostellers to share personal experiences and travel stories. Drawing from this, the present research views hostel accommodation as a service setting in which social interaction is central to the service experience.

Past studies on customer co-creation highlight the customer's role in delivering the service process, thus creating value for themselves as well as the service providers (Lusch \& Vargo, 2006; Finsterwalder \& Tuzovic, 2010; McColl-Kennedy \& Tombs, 2011; Grissemann \& Stokburger-Sauer, 2012; Johnston et al., 2012; Minkiewicz et al., 2014; Jaakkola \& Alexander, 2014; Rihova et al., 2014). For example, retail customers may make personal recommendations to each other about which products to buy, thus contributing towards the shopping experience. Similarly, in a spectator sports setting, the presence of fellow customers often add to the pleasurable overall atmosphere of the sporting experience. The topic of customer co-creation is especially crucial in the service-dominant (S-D) logic literature whereby it is proposed that the customer becomes a co-creator of value (Lusch \& Vargo, 2006). Specifically, the S-D logic highlights the value-creation process that occurs when a customer uses a product/service, rather than when the output is manufactured (Payne et al., 2008). The current research therefore suggests that within the hostel service setting, guests may be involved in the joint creation and consumption of service 
through their interactions with one another. For instance, Murphy (2001) examined interactions between backpackers to find out the way they disseminated information. Sorensen (2003) investigated how backpacker culture evolved through impromptu social interaction with other backpackers. Loker-Murphy and Pearce (1995) found that socialising with locals and fellow backpackers were significant elements of the backpacking experience. Additionally, Obenour et al.'s (2006) study showed a relationship between the social interactions among backpackers with their perceptions of the service experience.

In-depth interviews carried out by Murphy (2001) in Australian hostels illustrated that the interior boundaries of the hostel that encouraged social interaction were the dormitory rooms, communal eating, TV areas, common rooms and outdoor areas. The props or furnishings within these boundaries need to be comfortable, with 'home-like' touches to assist in creating a friendly atmosphere. The most important modifier is cleanliness, which encourages the guests to feel comfortable and spend more time within the boundaries. In terms of space, many respondents expressed a preference for smaller hostels, finding larger ones to be too impersonal, and have a relaxed attitude about privacy and personal space. Besides the environmental settings of the hostel, respondents also mentioned that having staff that are friendly and involved in social activities gives a hostel a good social atmosphere. For example, social activities with staff such as barbeques and sightseeing tours help to create a friendly atmosphere. Murphy's (2001) findings also indicated that hostels in remote destinations should provide opportunities for guests to meet other people, as there is little to do in the evenings. These findings suggest that hostels play an important role in facilitating social interaction and that merely providing shared spaces does not automatically foster interaction among backpackers.

\subsection{CONCEPTUAL FRAMEWORK}

The conceptual framework presented in Figure 1 summarises the discussion so far. In terms of the servicescape dimensions, past studies have established that a customer's evaluation of the service experience is influenced by both the physical and human elements of the servicescape (Tombs \& McColl-Kennedy, 2003; Obenour et al., 2006; Kwortnik, 2008; Papathanassis, 2012). However, little has been done to examine exactly how these two elements of the servicscape affect social interaction among customers, and how these interactions influence their post-consumption evaluation of the service experience. Existing literature has mainly focused on how the servicescape directly affects service experience evaluation (Kotler, 1973; Bitner, 1992; Hoffman \& Turley, 2002; Ezeh \& Harris 2007), thus leaving out the social aspects of the service experience. The present study attempts to fill this knowledge gap by answering the following research question: How does hostel servicescape design influence social interaction among guests and their evaluation of the service experience?

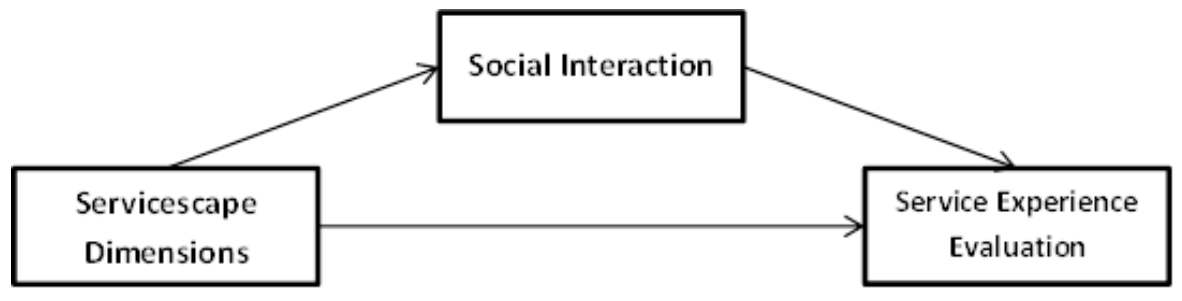

Figure 1 Conceptual framework

Based on the above conceptual framework, it is suggested that different dimensions of the servicescape encourage/discourage social interaction from taking place. As discussed previously, Mehrabian and Russell (1974) propose that the spatial arrangement of objects and persons, as well as architecture and room decorations all have an influence on the frequency and quality of social interactions. Additionally, noise, colour, light, humidity and odour may also affect social interaction (Argyle, Furnham \& Graham, 1981; Bowie \& Buttle, 2011).

Furthermore, the conceptual framework also serves to illustrate that the customer's evaluation of the service experience is determined by two major factors: firstly, their perception of the overall servicescapes and secondly, their overall positive/negative experiences of interacting with other customers. These interactions could be direct in nature, whereby face-to-face communications and activities occur between individuals, or indirect, whereby other individuals have a co-presence within the service setting.

From a practical standpoint, the findings from this research could provide recommendations for hostel operators in terms of the physical design and management of hostels. The design and placement of tangible items such as hostel rooms, equipment, furniture, fixtures and fittings may well influence customers' behaviours and interactions. For instance, kitchens designed to be large can provide a more conducive area for socialisation. Lounge areas with cosy sofas and cushions can also create a social atmosphere for the guests. In some cases, this means creating a special environment that facilitates social interaction between the guests, whereas in others, the environment should serve to allow guests to avoid other customers. Results of this research might also offer guidelines for hostel operators in terms of optimising space utilisation in order to maximise the duration of the service encounter and enhance the comfort of the customer. Integration of the customer into the service environment may function as a positioning strategy to target market segments attracted to social interaction and the type of customers present.

\subsection{CONCLUSION}

This paper has highlighted an under-researched area of co-creation of the service experience. It is argued that the environmental setting in which services occur is not just limited to the built physical surroundings, as originally suggested by Bitner (1992). The social aspects of the servicescape also play a role in the enhancement of the service experience. Theoretical models proposed by Kotler (1973), Mehrabian and 
Russell (1974), Baker (1986) and Bitner (1992) have established a useful foundation for understanding how environmental stimuli can evoke behavioural responses that encourage individuals to socially interact with others who are present in the same environment. Past research has shown that depending on different contexts and settings, social interaction can be central to the service experience (Jones, 1995; Martin, 1995; Tombs \& McColl-Kennedy, 2003; Nicholls, 2010). Hence, understanding how social interaction can be managed is crucial as such interaction may influence the individual's evaluation of the service experience. This is especially important if service providers intend to attract particular market segments that highly value the social aspects of the service experience. It is therefore recommended that future research should empirically test the proposed conceptual framework to investigate how each servicescape element can be explicitly manipulated to facilitate this interaction. Additionally, empirical evidence is also needed to examine how social interaction, be it positive or negative in nature, affects the way the service experience is evaluated.

\section{References}

Argyle, M., Furnham, A. \& Graham, J. A. (1981). Social Situations. Cambridge: Cambridge University Press.

Baker, J. (1986). The Role Of The Environment In Marketing Services: The Consumer Perspective In The Services Challenge: Integrating For Competitive Advantage. Eds. John A. Cepeil et al. Chicago, IL: American Marketing Association. 79-84.

Biesanz, J. (1941). Nazi Influence on German Youth Hostels. Social Force.19(4), 554-559.

Bitner, M. J. (1992). Servicescapes: The Impact Of Physical Surroundings On Customers And Employees. Journal of Marketing, 56, 57-71.

Bowen, B. E. \& Daniels, M. J. (2006).Hostelling As A Pathway To Cross-Cultural Understanding.Tourism Review International, 14, 189-199.

Bowie, D. \& Buttle, F. (2011). Hospitality Marketing: Principles and Practice. (2nd ed.). Oxford: Elsevier Ltd.

Butler, G. (2010). Challenging hostel user typologies: Motivations And Mobilities In Norway (Doctoral dissertation, University of Sunderland).

Cave, J., Thyne, M. \& Ryan, C. (2008). Perceptions Of Backpacker Accommodation Facilities: A Comparative Study of Scotland and New Zealand. In K. Hannam \& I. Ateljevic. (Eds.). Backpacker Tourism: Concepts and Profiles. Clevedon: Channel View Publications. 215-246.

Cohen, E. (2003). Backpacking: Diversity and change. Tourism and Cultural Change, 1, 95-110.

Donovan, R. J. \& Rossiter, J. R. (1982). Store Atmosphere: An Environmental Psychology Approach. Journal of Retailing, 58(1), 34-57.

Dubin, E. (2003). Preservation For the People: Seventy Years of American Youth Hostels. Unpublished Masters Thesis. University of Pennsylvania, USA.

Ezeh, C. \& Harris, L. C. (2007). Servicescape Research: A Review And A Research Agenda. The Marketing Review, 7(1), 59-78.

Hall, C. M. (2009).Sharing Space With Visitors: The Servicescape Of The Commercial Exurban Home. In P. Lynch, A. McIntoch \& H. Tucker (Eds.). The Commercial Home. London: Routledge.

Hannam, K., \& Diekmann, A. (2010). From Backpacking To Flashpacking: Developments In Backpacker Tourism Research. In K. Hannam \& A. Diekmann. (Eds.). Beyond Backpacker Tourism: Mobilities and Experiences. Clevedon: Channel View Publications. 1-7.

Harris, C. L. \& Ezeh, C. (2008).Servicescape And Loyalty Intentions: An Empirical Investigation. European Journal of Marketing, 42(3/4), 390-422.

Hecht, J. \& Martin, D. (2006). Backpacking And Hostel-Picking: An Analysis from Canada. International Journal of Contemporary Hospitality Management, 18 (1), 69-77.

Hoffman, K. D. \& Turley, L. W. (2002). Atmospherics, Service Encounters And Consumer Decision Making: An Integrative Perspective. Journal of Marketing Theory and Practice. 33-47.

Holahan, C. J. (1982). Environmental Psychology. New York: Random House, Inc.

Hottola, P. (2005). The metaspatialities of control management in tourism: Backpacking in India. Tourism Geographies, 7(1), 1-22.

Howard, R. W. (2007). Five Backpacker Tourist Enclaves. International Journal of Tourism Research, 9, 73-86.

Huang, J. \& Hsu, C. H. (2009a).The Impact Of Customer-To-Customer Interaction On Cruise Experience And Vacation Satisfaction. Journal of Travel Research, 49(1), 79-92.

Jarvis, J., \& Peel, V. (2010). Flashpacking in Fiji: Reframing The 'Global Nomad'in A Developing Destination. In K. Hannam \& A. Diekmann (Eds.). Beyond Backpacker Tourism: Mobilities and Experiences. Clevedon: Channel View Publications. 21-39.

Kotler, P. (1973). Atmospherics As A Marketing Tool. Journal of Retailing, 49(4), 48-64.

Kwortnik, R. J. (2008). Shipscape Influence On The Leisure Cruise Experience. International Journal of Culture, Tourism and Hospitality Research, 2 (4), $289-311$.

Markward, A. (2008). Backpackers: the next generation? (Doctoral dissertation, Auckland University of Technology).

Levy, S. E., Getz, D. \& Hudson, S. (2011). A Field Experimental Investigation Of Managerially Facilitated Consumer-To-Consumer Interaction. Journal of Travel \& Tourism Marketing, 28(6), 656-674

Martin, C. L. (1995). The Customer Compatibility Scale: Measuring Service Customer's Perceptions Of Fellow Customers. Journal of Consumer Studies and Home Economics, 19(3), 299-311.

McCulloch, J. (1992). The Youth Hostels Association: Precursors And Contemporary Achievements. The Journal of Tourism Studies, 3(1), $22-27$.

Mehrabian, A., \& Russell, J. A. (1974). An Approach to Environmental Psychology. Cambridge, MA: MIT press.

Mintel (2009). Youth Travel Accommodation - International. June 2009. Retrieved 20 April 2012 from Mintel Report Database http://academic.mintel.com/sinatra/oxygen_academic

Molz, J. \& Paris, C. M. (2013). The Social Affordances Of Flashpacking: Exploring The Mobility Nexus Of Travel And Communication. Mobilities , 10 (2), 173-192, Murphy, L. (2001). Exploring Social Interactions Of Backpackers. Annals of Tourism Research, 28(1), 50-67.

Musa, G. \& Thirumoorthi, T. (2011). Red Palm: Exploring Service Quality And Servicescape Of The Best Backpacker Hostel In Asia. Current Issues in Tourism, 14(2), $103-120$.

Nicholls, R. (2010). New Directions For Customer-To-Customer Interaction Research. Journal of Services Marketing, 24(1), 87-97.

Nilsson, E. \& Ballantyne, D. (2014). Reexamining The Place Of Servicescape In Marketing: A Service-Dominant Logic Perspective. Journal of Services Marketing, 28(5), 374-379.

Obenour, W. L., Patterson, M., Pedersen, P. \& Pearson, L. (2006).Conceptualization Of A Meaning-Based Research Approach For Tourism Service Experiences. Tourism Management, 27, 34-41.

O’Reilly, C. (2006). From Drifter To Gap Year Tourist: Mainstreaming Backpacker Travel. Annals of Tourism Research, 33(4), 998-1017.

Papathanassis, A. (2012). Guest-to-Guest Interaction On Board Cruise Ships: Exploring Social Dynamics And The Role Of Situational Factors. Tourism Managemen, $33(5), 1148-1158$.

Paris, C. M. (2012). Flashpackers: An Emerging Sub-Culture? Annals of Tourism Research, 39(2), 1094-1115.

Richards, G. \& Wilson, J. (2004). The Global Nomad: Backpacker Travel in Theory and Practice. Clevedon: Channel View Publications.

Teo, P. \& Leong, S. (2006). A postcolonial analysis of backpacking. Annals of Tourism Research, 33(1). 109-131.

Tombs, A. \& McColl-Kennedy, J. R. (2003). Customers As Spatial And Social Influences On Other Customers In The Social Servicescape, Paper Presented at the Australian and New Zealand Marketing Academy Conference (ANZMAC2003), Adelaide, Australia, 1-3 December 2003.

Wilson, J. \& Richards, G. (2008). Suspending Reality: An Exploration Of Enclaves And The Backpacker Experience. In J. Wilson \& G. Richard (Eds.). Backpacker Tourism: Concepts and Profiles. Clevedon: Channel View Publications. 9-25.

Westerhausen, K., \& Macbeth, J. (2003). Backpackers And Empowered Local Communities: Natural Allies In The Struggle For Sustainability And Local Control?.Tourism Geographies, 5(1), 71-86. 